\title{
Antisense Orientation
}

National Cancer Institute

\section{Source}

National Cancer Institute. Antisense Orientation. NCI Thesaurus. Code C63551.

Having a DNA sequence complementary to that of a messenger RNA molecule; the noncoding strand in double-stranded DNA. 